UDC 616.9

DOI: 10.15587/2519-4798.2021.238014

\title{
A DESCRIPTIVE STUDY OF COVID-19 AT A TERTIARY CARE HOSPITAL
}

\author{
Amit Mittal, Manoj Kumar Singh, Rajeev Kumar, Deepti Mandsorwale
}

Coronavirus disease 2019 (abbreviated "COVID-19”) is an emerging respiratory disease that is caused by a novel coronavirus and was first detected in December 2019 in Wuhan, China. The cases of COVID-19 infection since then were showing increasing trend in all over the world.

The aim: to study the epidemiological distribution and determinants of COVID-19 pandemic.

Methods: it is a descriptive study carried out at a tertiary care hospital of India. The population comprised of patients admitted in the hospital. Sample size comprised of all the subjects admitted in the hospital with established COVID 19 +ve cases. The duration of study was April 2020 to June 2020. The study was approved by the Institutional Ethical committee and Informed consent was obtained from each subject before the conduct of the study. Data collection was done by a pre-structured questionnaire. Data entry and analysis was done using SPSS version 20 software.

Results: out of total 38 COVID-19 +ve cases, $95 \%$ were male and $5 \%$ female ant the maximum numbers of cases ranges between 36-40 years of age group with the median age of 32 years.53\% of cases were Muslim and $47 \%$ Hindu by religion. The median duration of stay in hospital of all COVID-19 +ve cases was11 day that on further differentiation with co-morbidity was 15 days and 11.5 without any co-morbidity. The median duration taken between $1^{\text {st }}$ sample taken and report provided was 2 days, between $2^{\text {nd }}$ sample taken and report provided 1 day and between $1^{\text {st }}$ and $2^{\text {nd }}$ sample taken was 11 days.

Conclusions: present study concluded that middle age persons were affected in majority which may be due to more exposure to public places. Co-morbidities are strong predictors of requirement for admission and duration of stay at hospital

Keywords: COVID-19, descriptive study, tertiary care hospital, India

(C) The Author(s) 2021

This is an open access article under the Creative Commons CC BY license

How to cite:

Mittal, A., Singh, M. K., Kumar, R., Mandsorwale, D. (2021). A descriptive study of COVID-19 at a tertiary care hospital. ScienceRise: Medical Science, 4 (43), 00-00. doi: http://doi.org/10.15587/2519-4798.2021.238014

\section{Introduction}

Coronavirus disease 2019 (abbreviated "COVID19 ") is an emerging respiratory disease that is caused by a novel coronavirus and was first detected in December 2019 in Wuhan, China. The disease is highly infectious, and its main clinical symptoms include fever, dry cough, fatigue, myalgia, and dyspnea [1]. Coronavirus is one of the major pathogens that primarily target the human respiratory system. Previous outbreaks of corona viruses (CoVs) include the severe acute respiratory syndrome (SARS)-CoV and the Middle East respiratory syndrome (MERS)-CoV which have been previously characterized as agents that are a great public health threat. In late December 2019, a cluster of patients was admitted to hospitals with an initial diagnosis of pneumonia of an unknown etiology. These patients were epidemiologically linked to seafood and wet animal wholesale market in Wuhan, Hubei Province, China [2, 3].

The chronology of COVID-19 +ve infections is as follows. The first cases were reported in December 2019 [4]. From December 18, 2019 till December 29, 2019, five patients were hospitalized with acute respiratory distress syndrome and one of these patients died [5]. By January 2, 2020, 41 hospitalized patients were identified as having laboratory confirmed COVID-19 +ve infection, less than half of these patients had pre-existing comorbidities including Diabetes, Hypertension, and Cardiovascular disease [6]. As of January 30, 2020, 7734 cases have been confirmed in China and 90 other cases have also been reported from a number of countries that include Taiwan, Thailand, Vietnam, Malaysia, Nepal, Sri Lanka, Cambodia, Japan, Singapore, Republic of Korea, United Arab Emirates, United States, The Philippines, India, Australia, Canada, Finland, France, and Germany. The case fatality rate was calculated to be $2.2 \%$ (170/7824) [7]. As the situation got worse, the WHO declared the outbreak as the Public Health Emergency of International Concern (PHEIC) [8].

On 11 February 2020, the International Committee on Taxonomy of Viruses renamed the virus as Severe Acute Respiratory Syndrome Coronavirus 2 (SARSCoV2) [9] and WHO announced the epidemic disease caused by SARS-CoV-2 as coronavirus disease 2019 (COVID19) [10]. It is currently speculated that the outbreak of COVID-19 inWuhan is linked with consumption of wild animals, meat and seafood. According to WHO, the environmental samples taken from Huanan seafood Market were tested positive for SARS-CoV-2 [11], but the specific animals associated with the virus have not been identified. Based on previous evidence the bats are host of more than 30 coronaviruses [12]. Cohen pointed out Wuhan Huanan seafood market was not the only origin of SARS-CoV-2 by analyzing the epidemiology of 41 cases in the earliest study. Pangolins may act as one of the intermediate hosts. More work is needed to provide more precise information about original reservoir and intermediate hosts of SARS-CoV-2 [13]. Age and comorbidities were found to be strong predictors for hos- 
pital admission and critical illness and mortality in people with covid-19 [14].

The aim of the research was to understand epidemiological distribution and determinants of COVID-19.

\section{Objectives}

1. To study the distribution of disease with respect to time, place and person.

2. To study various factors associated with stay at tertiary care hospital.

3. Outcome of COVID-19 +ve cases at tertiary care hospital.

\section{Materials \& methods}

Present study is a descriptive cross-sectional study. The study was carried out at a tertiary care hospital of a medical college located in an urban area of western Uttar Pradesh, India. The study population comprised of patients admitted in the tertiary care hospital of all age groups. The cases selected for study were confirmed rtPCR COVID-19 +ve, admitted in the tertiary care hospital during the study period.

Inclusion criteria: all COVID-19 patients admitted at tertiary care hospital during study period.

Exclusion criteria: all COVID-19 patients with comorbid mental illness.

Convenient sample size was taken of 38 patients. The study was conducted from date of $1^{\text {st }}$ case admission to date of last case discharged (April 2020 to June 2020). Ethical clearance was obtained from the S.M.M.HGovt Medical College, Saharanpur institutional ethics committee, dated 22 July 2020, with reference number-IEC 1622-05-2020, before the start of the study. Informed consent was obtained from each subject before the conduct of the study. Cases, who met the inclusion criteria, were selected and interviewed. Patients were approached to be part of study after fulfilling inclusion and exclusion criteria, explained in detail about the purpose of the study and about methodology prior to data collection. In case of unwillingness to participate, the next patient was approached. Data collection was done by a pre-tested and pre-structured questionnaire. At the end of data collection, necessary health education was imparted to all members of study cases. The health hazard inherent in this habit was explained to everyone and the idea to persuade the smokers to give up the habit and non-smokers not to resort to it. Data entry was done by researcher and analyzed using SPSS version 20 software. The data was analyzed with the help of bio-statistician extensively involved in health research.

\section{Results}

The maximum number of cases was from 26-30 years age group out of total 38 COVID-19 +ve cases with median age of 32 years (Table 1).
Table 1

Distribution of COVID-19 cases by age, at tertiary care hospital, Saharanpur, U.P., India April-June 2020

\begin{tabular}{|c|c|c|}
\hline \multirow[b]{2}{*}{ Age } & Median & Range \\
\hline & 32 years & $\begin{array}{l}03 \text { months to } \\
80 \text { years }\end{array}$ \\
\hline Age group(years) & $\mathrm{n} / \mathrm{N}$ & Percentage \\
\hline$<1$ & $1 / 38$ & $2 \%$ \\
\hline $1-5$ & $0 / 38$ & $0 \%$ \\
\hline $6-10$ & $1 / 38$ & $2 \%$ \\
\hline $11-15$ & $0 / 38$ & $0 \%$ \\
\hline $16-20$ & $2 / 38$ & $5 \%$ \\
\hline $21-25$ & $4 / 38$ & $10.5 \%$ \\
\hline $26-30$ & $9 / 38$ & $24 \%$ \\
\hline $31-35$ & $4 / 38$ & $10.5 \%$ \\
\hline $36-40$ & $2 / 38$ & $5 \%$ \\
\hline $41-45$ & $3 / 38$ & $8 \%$ \\
\hline $46-50$ & $1 / 38$ & $2 \%$ \\
\hline $51-55$ & $3 / 38$ & $8 \%$ \\
\hline $56-60$ & $2 / 38$ & $5 \%$ \\
\hline $61-65$ & $4 / 38$ & $10.5 \%$ \\
\hline $66-70$ & $1 / 38$ & $2 \%$ \\
\hline $71-75$ & $0 / 38$ & $0 \%$ \\
\hline $76-80$ & $1 / 38$ & $2 \%$ \\
\hline$>80$ & $0 / 38$ & $0 \%$ \\
\hline
\end{tabular}

Out of 38 COVID-19 +ve cases, $52.7 \%$ cases were Muslim and $47.3 \%$ Hindu by religion and about $95 \%$ were male and $5 \%$ female (Table 2 ).

Table 2

Distribution of COVID-19 cases by religion and gender, at Tertiary care hospital, Saharanpur, U.P., India AprilJune 2020

\begin{tabular}{|c|c|c|}
\hline Religion & $\mathbf{n} / \mathbf{N}$ & Percentage \\
\hline Hindu & $18 / 38$ & $47.3 \%$ \\
\hline Muslim & $20 / 38$ & $52.7 \%$ \\
\hline Others & $0 / 38$ & Zero \\
\hline Gender & $\mathbf{n} / \mathbf{N}$ & Percentage \\
\hline Female & $2 / 38$ & $05.2 \%$ \\
\hline Male & $36 / 38$ & $94.8 \%$ \\
\hline
\end{tabular}

The median duration of stay in hospital of all COVID-19 +ve cases was 11 days. Further differentiated into with co-morbidities 15 days and without any comorbidity 11.5 days (Tab. 3). The median duration taken between 1st sample collected and report provided was 2 days, between 2 nd sample collected and report provided 1 day and between 1 st and 2nd sample collected was 11 days (Table 3 ).

The percentage of COVID-19 cases with comorbidities was 23.6 (9/38). And $08 \%$ (3/38) of the cases were kept on a ventilator and no death was reported during the study period. Maximum numbers of cases were admitted on $1^{\text {st }}$ June, 2020 at this Tertiary care hospital, Saharanpur (Fig. 1).

Maximum numbers of cases were reported from Saharanpur Tehsil among all the Tehsils under Saharanpur district (Fig. 2). 
Table 3

Distribution of COVID-19 cases by duration of hospital stay and laboratory confirmation at tertiary care hospital, Saharanpur, U.P., India April-June 2020

\begin{tabular}{|l|c|c|}
\hline \multicolumn{1}{|c|}{ Parameters } & Median & Range \\
\hline Duration of stay in hospital & 11 days & $09-18$ days \\
\hline Duration of stay in hospital with co-morbidities & 15 days & $06-18$ days \\
\hline Duration of stay in hospital without any co-morbidities & 11.5 days & $09-22$ days \\
\hline Duration between 1st sample taken and report provided & 02 days & $01-07$ days \\
\hline Duration between 2nd sample taken and report provided & 01 day & $01-08$ days \\
\hline Duration between 1st and 2nd sample taken & 11 days & $10-17$ days \\
\hline
\end{tabular}

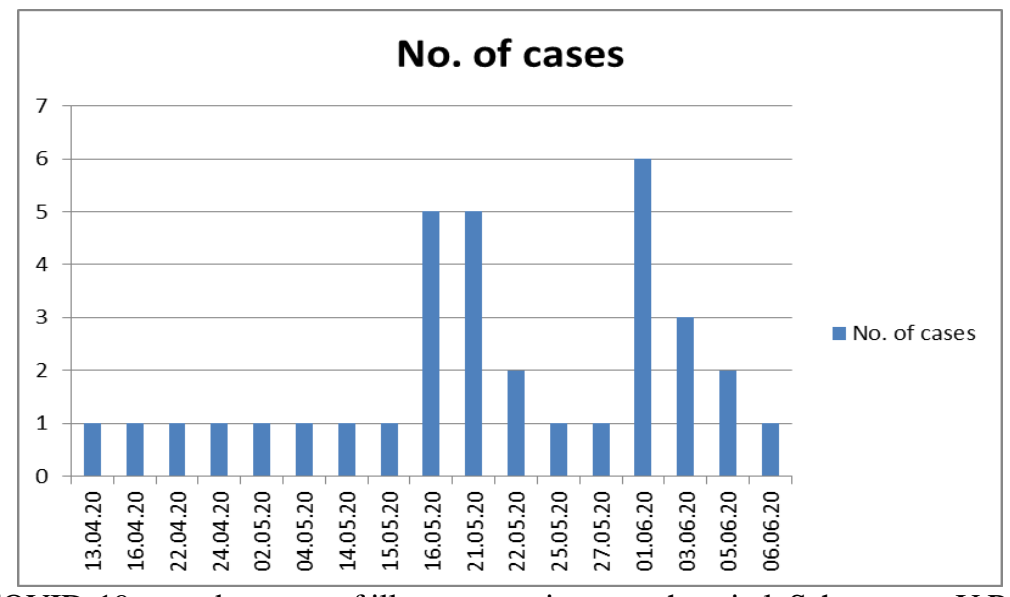

Fig. 1. Distribution of COVID-19 cases by onset of illness, at tertiary care hospital, Saharanpur, U.P., India, April-June 2020

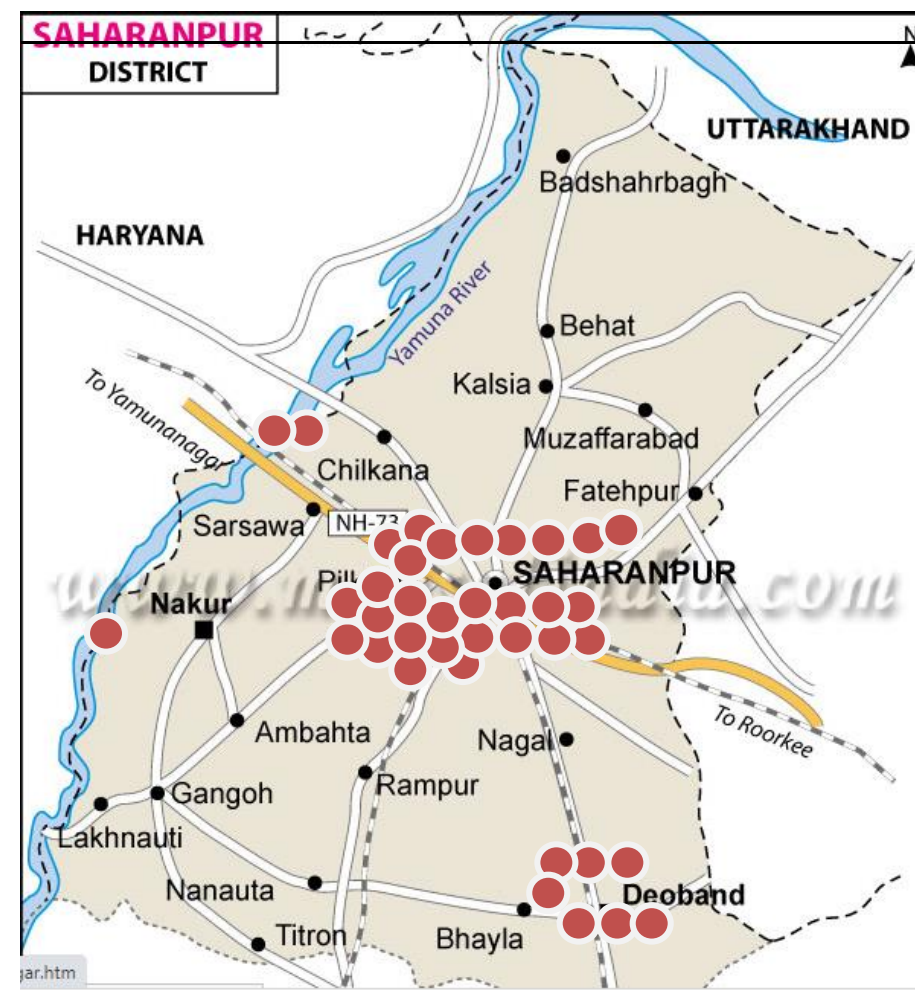

Fig. 2. Distribution of COVID-19 +ve cases at Tertiary care hospital, Saharanpur, U.P., India, April-June 2020

\section{Discussion}

Study reported the maximum number of cases from 26-30 years of age group with median age of 32 years. Similar to present study reported median age of patients was ranged from 41 to 57 years [15]. Present study reported more than half of cases were from Muslim religion $(53 \%)$ and predominantly male by gender. Male patients made up the majority of cases with the proportion of 50-75\% [15]. The study reported that median duration of hospital stay of COVID-19 +ve cases with co-morbidities was slightly higher than without comorbidities. The median duration reported between 1 st sample collected and reported was similar to 2 nd sample collected and reported. Present study reported one fourth of COVID-19 cases having co-morbidities with chronic diseases. Approximately 25.2-50.5\% SARS-CoV-2 infected patients had one or more underlying diseases, including Hypertension, Diabetes, Chronic Obstructive 
Pulmonary Disease, Cardiovascular disease, and malignancy [16]. The epidemic curve of present study showed increasing trend and majority of cases belong to $\mathrm{Sa}$ haranpur Tehsil.

\section{Limitations of the study:}

a) A major limitation of our study is that it was entirely conducted at a single tertiary care facility, with the inherent referral bias.

b) The results of this study may not be generalised to the entire community due to the hospital setting of the current study.

c) The sample size is very small and conveniently taken in limited resource settings.

Prospects for further research - COVID-19 has potential to become pandemic and present study contributes epidemic attributes in limited settings. There are very few studies on distribution, determinants and risk factors at large scale. There is a huge research gap for prevention and control of COVID-19. To fill the research gap further advance study design is required.

\section{Conclusion}

Overall, we found that middle age persons were majorly affected which may be due to more exposure to public places. Comorbidities are strong predictors of requirement for admission and duration of stay at hospital. Population belonging to urban Tehsil are on more risk to acquire the disease. Further research is needed to establish determining factors for outcome and progression of COVID-19 Cases.

\section{Conflict of interest}

The authors declare that they have no conflicts of interest.

\section{Financing}

The study was performed without financial support.

\section{References}

1. Zhong, B.-L., Luo, W., Li, H.-M., Zhang, Q.-Q., Liu, X.-G., Li, W.-T., Li, Y. (2020). Knowledge, attitudes, and practices towards COVID-19 among Chinese residents during the rapid rise period of the COVID-19 outbreak: a quick online cross-sectional survey. International Journal of Biological Sciences, 16 (10), 1745-1752. doi: http://doi.org/10.7150/ijbs.45221

2. Bogoch, I. I., Watts, A., Thomas-Bachli, A., Huber, C., Kraemer, M. U. G., Khan, K. (2020). Pneumonia of unknown aetiology in Wuhan, China: potential for international spread via commercial air travel. Journal of Travel Medicine, 27 (2). doi: http://doi.org/10.1093/jtm/taaa008

3. Lu, H., Stratton, C. W., Tang, Y. (2020). Outbreak of pneumonia of unknown etiology in Wuhan, China: The mystery and the miracle. Journal of Medical Virology, 92 (4), 401-402. doi: http://doi.org/10.1002/jmv.25678

4. Du Toit, A. (2020). Outbreak of a novel coronavirus. Nature Reviews Microbiology, 18 (3), 123-123. doi: http://doi.org/10.1038/ s41579-020-0332-0

5. Ren, L.-L., Wang, Y.-M., Wu, Z.-Q., Xiang, Z.-C., Guo, L., Xu, T. et. al. (2020). Identification of a novel coronavirus causing severe pneumonia in human: a descriptive study. Chinese Medical Journal, 133 (9), 1015-1024. doi: http://doi.org/10.1097/cm9.0000000000000722

6. Huang, C., Wang, Y., Li, X., Ren, L., Zhao, J., Hu, Y. et. al. (2020). Clinical features of patients infected with 2019 novel coronavirus in Wuhan, China. The Lancet, 395 (10223), 497-506. doi: http://doi.org/10.1016/s0140-6736(20)30183-5

7. Bassetti, M., Vena, A., Giacobbe, D. R. (2020). The novel Chinese coronavirus (2019- nCoV) infections: Challenges for fighting the storm. European Journal of Clinical Investigation, 50 (3). doi: http://doi.org/10.1111/eci.13209

8. Zarocostas, J. (2020). What next for the coronavirus response? The Lancet, 395 (10222), 401. doi: http://doi.org/10.1016/s01406736(20)30292-0

9. International Committee on Taxonomy of Virus (2020). Naming the 2019 Coronavirus. Available at: https://talk.ictvonline.org/

10. Notice of the National Health Commission of the People's Republic of China on revising the English name of novel coronavirus pneumonia (2020). Available at: http://www.nhc.gov.cn/yzygj/s7653p/202002/33393aa53d984ccdb1053a52b6bef810.shtml

11. Gralinski, L. E., Menachery, V. D. (2020). Return of the Coronavirus: 2019-nCoV. Viruses, 12 (2), 135. doi: http://doi.org/10.3390/v12020135

12. Phan, T. (2020). Novel coronavirus: From discovery to clinical diagnostics. Infection, Genetics and Evolution, 79, 104211. doi: http://doi.org/10.1016/j.meegid.2020.104211

13. Cohen, J. (2020). Wuhan seafood market may not be source of novel virus spreading globally. Science. doi: http://doi.org/10.1126/science.abb0611

14. Petrilli, C. M., Jones, S. A., Yang, J., Rajagopalan, H., O’Donnell, L., Chernyak, Y. et. al. (2020). Factors associated with hospital admission and critical illness among 5279 people with coronavirus disease 2019 in New York City: prospective cohort study. BMJ, 396. doi: http://doi.org/10.1136/bmj.m1966

15. Xu, X.-W., Wu, X.-X., Jiang, X.-G., Xu, K.-J., Ying, L.-J., Ma, C.-L. et. al. (2020). Clinical findings in a group of patients infected with the 2019 novel coronavirus (SARS-Cov-2) outside of Wuhan, China: retrospective case series. BMJ, 386. doi: http://doi.org/10.1136/bmj.m606

16. Guan, W., Ni, Z., Hu, Y., Liang, W., Ou, C., He, J. et. al. (2020). Clinical characteristics of 2019 novel coronavirus infection in China. doi: http://doi.org/10.1101/2020.02.06.20020974

Received date 18.05.2021

Accepted date 22.06.2021

Published date 30.07.2021

Amit Mittal, PhD, Assistant Professor, Department of Community Medicine, Shaikh-Ul-Hind Maulana Mahmood Hasan Medical College, Ambala Road, Saharanpur, India, 247001

Manoj Kumar Singh, MD, Assistant professor, Department of Internal Medicine, Shaikh-Ul-Hind Maulana Mahmood Hasan Medical College, Ambala Road, Saharanpur, India, 247001

Rajeev Kumar, MD, Assistant professor, Department of Community Medicine, Shaikh-Ul-Hind Maulana Mahmood Hasan Medical College, Ambala Road, Saharanpur, India, 247001

Deepti Mandsorwale*, PhD, Assistant Professor, Department of Biochemistry, Shaikh-Ul-Hind Maulana Mahmood Hasan Medical College, Ambala Road, Saharanpur, India, 247001 